Article

\title{
Transcript Abundance Patterns of 9- and 13-Lipoxygenase Subfamily Gene Members in Response to Abiotic Stresses (Heat, Cold, Drought or Salt) in Tomato (Solanum lycopersicum L.) Highlights Member-Specific Dynamics Relevant to Each Stress
}

\author{
Rakesh K. Upadhyay 1,2,*(D), Avtar K. Handa ${ }^{2}$ (D) and Autar K. Mattoo ${ }^{1, *}$ \\ 1 Sustainable Agricultural Systems Laboratory, USDA-ARS, \\ Henry A. Wallace Beltsville Agricultural Research Center, Beltsville, MD 20705-2350, USA \\ 2 Department of Horticulture and Landscape Architecture, Purdue University, W. Lafayette, \\ IN 47907-2010, USA \\ * Correspondence: rakesh.upadhyay@usda.gov or rkumarup@purdue.edu (R.K.U.); \\ autar.mattoo@usda.gov (A.K.M.)
}

Received: 18 July 2019; Accepted: 3 September 2019; Published: 5 September 2019

\begin{abstract}
Lipoxygenases (LOXs; EC 1.13.11.12) catalyze the oxygenation of fatty acids to produce oxylipins including the jasmonate family of plant hormones. The involvement of jasmonates in plant growth and development and during abiotic stress has been documented, however, the response and regulation of each member of the LOX gene family under various abiotic stresses is yet to be fully deciphered. Previously, we identified fourteen members of the tomato LOX gene family, which were divisible into nine genes representing the 9-LOX family members and five others representing the 13-LOX family members based on the carbon oxidation position specificity of polyunsaturated fatty acids. Here, we have determined the transcript abundance patterns of all the 14 LOX genes in response to four independent abiotic stresses, namely, heat, cold, drought and salt. Our results show that each of these stresses leads to a time-dependent, variable or indifferent response of specific and different set(s) of LOX gene members of both subfamilies, differentiating functional relevance of the 14 LOX genes analyzed. Out of the 14 gene members, three LOX genes were expressed constitutively or were non-responsive to either heat (SILOX9), cold (SILOX9) or salt (SlLOX4) stress. An in-silico LOX gene promoter search for stress-responsive elements revealed that only some but not all of the LOX genes indeed are decorated with specific and known stress responsive cis-acting elements. Thus, these data implicate some other, yet to be discovered, cis-acting elements present in the LOX gene family members, which seemingly regulate tomato responses to defined abiotic stresses presented here.
\end{abstract}

Keywords: Solanum lycopersicum; LOX; lipoxygenase; methyl jasmonate; hormone; gene expression; abiotic stresses

\section{Introduction}

Plants being sessile are constantly exposed to changes in the environment. Such exposure to different abiotic stresses-heat, cold, drought or salinity-affects photosynthesis, crop yield, nutrition and fruit set leading to reduced crop productivity. Some plants are better than others in developing mechanisms to counterbalance environmental stress conditions. Plant responses to environmental changes have been documented in some species and clearly complex endogenous 
networking is apparent involving, among other responders, many unique molecules including hormones, transcriptional factors and unique genes [1,2]. Among the hormones, the jasmonate (JA) family members are considered as plant stress hormones since they have been shown to activate plant defense against environmental stresses, including cold, high temperatures, drought and salinity [3-10]. Jasmonates are a class of oxylipins derived from fatty acid hydroperoxides and involve the enzyme lipoxygenase (linoleate: Oxygen oxidoreductase, EC 1.13.11.12 [11,12].

LOX is a family of non-heme-iron-containing fatty acid dioxygenases widely distributed in both plants and animals [13]. LOXs are broadly classified into two sub-families, 9-LOX and 13-LOX, based on the preferred addition of molecular oxygen either at carbon atom 9 or 13 of the hydrocarbon backbone, respectively [7]. JA biosynthesis is catalyzed by 13-LOXs via 13(S)-hydroperoxy-octadecatrienoic acid, which is a substrate for several enzymes including the terminal allene oxide synthase (AOS) [14,15], while the 9-LOXs catalyze the synthesis of plant defense-related 9(S)-hydroperoxy-octadecatrienoic acid [16]. The subfamily of 9-LOX proteins is relatively more similar ( $60 \%)$ than the 13-LOXs protein subfamily $(\sim 35 \%)$ [17].

LOX enzymes are encoded by a multi gene family and are intrinsic to plant growth and development [18]. Multiple genes have been reported in various plant species including six in Arabidopsis; 14 each in potato, tomato and rice; 15 in medicago; 18 in grape; 19 in soyabean; 20 in poplar; 23 in apple and cucumber and 122 in six legumes [19-26]. The 13-LOX derived oxylipins including JA and MeJA have been characterized for their roles during plant development and in response to biotic and abiotic stresses [27].

Increased LOX activity has been correlated with salt tolerance in tomato seedlings [28]. CaLOX1 was reported to modulate abiotic stress responses via rapid scavenging of ROS and activation of defense-related marker genes in pepper [29]. The persimmon 9-LOX gene DkLOX3 was found to enhance tolerance to abiotic stress but also promoted senescence [30]. Tomato SILOX4/D was linked to jasmonate biosynthesis during plant development and defense [31] as well as to wound-induced stress [26]. It is also known that SlLOX4/D mutant, spr8 (suppressor of prosystemin-mediated responses8), had jasmonate-dependent immune deficiencies ranging from the suppression of wound-responsive genes and severely compromised resistance to Helicoverpa armigera and Botrytis cinerea [32]. Jasmonate is known to induce the PDF1.2 transcription factor in Arabidopsis [33] and heat shock-regulated sesquiterpene synthesis in Aquilaria sinensis [34]. AtLOX2 [35] and AtLOX6 [36] transcripts have been linked to long-distance signaling in plants. It is also accepted now that LOX activity is a biological marker in plant stress tolerance [37].

We previously identified 14 LOX genes in the tomato genome [26]. Here, we delineate specific transcriptional responses of these LOX gene members in tomato leaves independently exposed to cold, heat, drought or salinity, stresses that impede plant growth. These findings link and further validate their usefulness as biological markers in stress tolerance/response/mitigation.

\section{Materials and Methods}

\subsection{Plant Material}

Wild type tomato (Solanum lycopersicum cv. Ailsa Craig) plants were grown in a temperature-controlled greenhouse under natural light conditions.

\subsection{Abiotic Stress Treatments and Sample Collection}

Four weeks old (28 days after transplanting) tomato plants were independently given a known stress as follows. Heat treatment was given in a growth chamber (EGC Corp., Chagrin Falls, OH, USA) with day/night $(16 / 8 \mathrm{~h})$ photoperiod, temperature $42{ }^{\circ} \mathrm{C} \pm 0.15^{\circ} \mathrm{C}$ and relative humidity $(\mathrm{RH})$ of $50-70 \%$. Leaf samples were then collected at $0,0.5,1,6,12$ and $24 \mathrm{~h}$. Cold treatment $\left(4^{\circ} \mathrm{C}\right)$ was given to whole tomato plants in a walk-in cold room at $200 \mu \mathrm{mol} / \mathrm{m}^{2}$ light and $16 / 8 \mathrm{~h}$ photoperiod. Leaf samples were then collected at $0,1,6,12$ and $24 \mathrm{~h}$. Salt and drought treatments were given in a temperature-controlled 
greenhouse under natural light. Salt treatment involved irrigation of plants with $200 \mathrm{~mL}$ of $200 \mathrm{mM}$ $\mathrm{NaCl}$ solution in a container containing metromix 360 soil (Sun Gro Horticulture, Agawam, MA, USA). Leaf samples were then collected at 0, 2, 6, 48 and $96 \mathrm{~h}$. Drought treatment involved withholding watering of plants for seven days (168 h). Leaf samples were collected at $0,24,48,72$ and $168 \mathrm{~h}$ during which time watering was withheld. All the harvested samples were immediately frozen in liquid nitrogen and stored at $-70^{\circ} \mathrm{C}$ until used [38]. A minimum of three biological replicates were used for each time point where each biological replicate comprised of two technical replicates $(n=6)$. For each stress treatment, the 3rd leaf from the top was collected to maintain consistency, and three biological replicates were used. All experiments were repeated twice.

\subsection{Mining the S. lycopersicum LOX Transcriptome}

Transcriptome data for domesticated tomato (S. lycopersicum cv. Heinz) for the LOX gene family leaf tissue was extracted from the International Tomato Genome Sequencing Consortium (SGN; solgenomics.net) database (version ITAG 2.4). Reads per kilobase of transcript per million (RPKM) mapped reads values were retrieved, analyzed and are presented as heat maps. Heat maps were generated as previously described (https://discover.nci.nih.gov/cimminer/) [26,39].

\subsection{Total RNA Extraction, Complementary DNA Synthesis and Quantitative RT-PCR}

Frozen tomato leaf samples were ground with liquid nitrogen in a pestle and mortar to a fine powder. Total RNA was extracted from $100 \mathrm{mg}$ powdered tissue using Plant RNeasy kit as per the manufacturer's instructions (Qiagen, Germantown, MD, USA). Isolated RNA was treated with RNase-Free DNase (Qiagen) and cleaned using an RNeasy Mini Kit (Qiagen). RNA samples with an $A_{260 / 280}$ ratio of 1.8-2 were subjected to agarose gel electrophoresis to ensure the presence of intact ribosomal RNA (rRNA) band ratios and selected for complementary DNA (cDNA) preparation [40]. A total of $2 \mu \mathrm{g}$ RNA was used for cDNA synthesis using iScript Advanced cDNA synthesis kit (Bio-Rad, Hercules, CA, USA). Complementary DNA was diluted 10-fold for further use. Quantitative real-time PCR (qRT-PCR) was performed using SsoAdvanced Universal SYBR Green Supermix (Bio-Rad) in a Bio-Rad cycler (CFX96 Bio-Rad Real Time PCR machine). PCR conditions applied were: $95^{\circ} \mathrm{C}$ for $10 \mathrm{~min}, 95^{\circ} \mathrm{C}$ for $15 \mathrm{sec}$ and $60{ }^{\circ} \mathrm{C}$ for $60 \mathrm{~s}$ (40 cycles), followed by a melt curve analysis [39]. Relative $C_{t}$ values of gene expression were quantified using the $\Delta \Delta C_{T}$ method [41]. Reference genes, SITIP41 and SIUBI3, were used to normalize the expression of the target genes, and final data were calculated based on the geometric means of both $[42,43]$. Relative $C_{t} / C_{q}$ cycle was calculated by the Bio-Rad CFX Manager 3.1 based on the MIQE (minimum information for the publication of quantitative real-time PCR experiments) guidelines [44]. Relative fold changes were calculated as previously described [26,39]. Primer sequences used for qRT-PCR are listed in Table S1 with their SGN identity numbers. Relative qRT-PCR data represent average \pm standard deviation from a minimum of three independent biological replicates for each gene.

\subsection{Prediction of Abiotic Stress Related Cis-Regulatory Elements in SlLOX Promoters}

For identification of cis-regulatory elements in the tomato LOX genes, proximal promoter sequences $(-) 2 \mathrm{~Kb}$ upstream to ATG for each LOX gene, were extracted from SGN. The upstream sequences were analyzed using the PlantCARE promoter analysis tool [45].

\subsection{Data Analysis}

XLSTAT suite was used for statistical analysis. A one-way ANOVA was performed using a Tukey (HSD) test. Significant differences in the data from abiotic stress experiments were calculated against non-treated control $(0 \mathrm{~h})$ samples and were categorized at ${ }^{*} p<0.05,{ }^{* *} p<0.01$ and ${ }^{* *} p<0.001$ for each analysis as described previously $[39,46]$. 


\section{Results}

\subsection{Lipoxygenases Catalyze Synthesis of Oxylipin Signaling Molecules}

Plant lipoxygenases (LOXs) classify into 9-LOX and 13-LOX enzymes involved in the biosynthesis of oxylipins, including jasmonic acid and its derivatives. The 9-LOX enzyme catalyzes the conversion of 18:2 linoleic acid (LA) and 18:3 linolenic acid, respectively, to 9-hydroperoxide octadecadi(tri)enoic acids (9-HPOD/T) while the 13-LOX enzyme catalyzes the synthesis of 13-hydroperoxide octadecatrienoic acid (13-HPOT) from linoleic/linolenic acids (Figure 1). Allene oxide synthase (AOS) converts 9-HPOD/T to 9,10-epoxy octadecadienoic acid (9,10-EOD), which is followed by formation of either 10-OPDA (oxo-phytodienoic acid) or ketols (Figure 1). The 13-LOX enzyme catalyzes the formation of 13-HOPT, which generate substrate for the synthesis of jasmonic acid [47,48]. We previously identified 9-LOX and 13-LOX sub-families of tomato based on the catalysis of substrate carbon oxidation position and their likeness with previously characterized plant LOXs [26]. Tomato 9-LOX sub-family constitutes nine genes, namely, SLLOX1, 2, 5, 6, 7, 8, 9, 13 and 14 and the 13-LOX sub-family is comprised of five genes, namely, SlLOX3, 4, 10, 11 and 12. The predicted open reading frames for the members of LOX family range from 2526 to 2736 nucleotides [26].

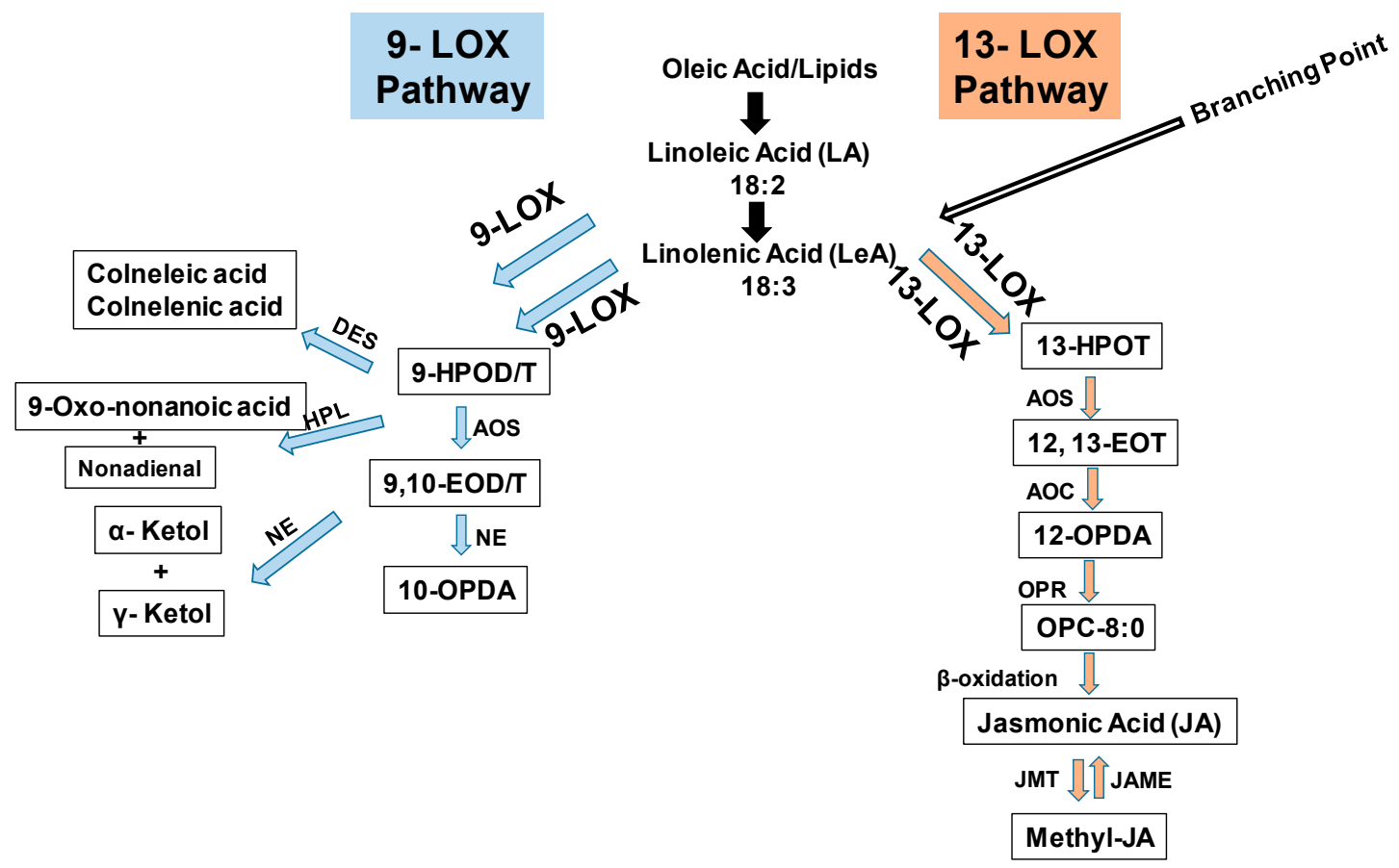

Figure 1. A schematic representation of 9-LOX and 13-LOX pathways in plants [47,48]. Abbreviations: HPOD: 9 or 13-hydroperoxide linolenic acid; 13(S) or 9(S)-hydroperoxylinolenic acid; OPDA: 12-oxo-phytodienoic acid; LOX: Lipoxygenase; AOS: Allene oxide synthase; AOC: Allene oxide cyclase; OPR: Oxo-phytodienoic acid reductase; JMT: Jasmonic acid carboxyl methyltransferase; JAME: Methyl jasmonate esterase; HPL: Hydroperoxide lyase; DES: Divinyl ether synthase. NE: Non-enzymatic.

\subsection{LOX Sub-Family Gene Expression in the Domesticated Tomato (S. lycopersicum cv. Heinz)}

Expression patterns of $L O X$ gene family members in leaf tissue were created by analyzing the available leaf transcriptome data for the SILOX gene family for S. lycopersicum (SGN). Both the 9-LOX and 13-LOX sub-family members were differentially expressed in tomato leaf tissues (Figure 2) [26]. Among the 9-LOX subfamily genes, SILOX6 was the highly expressed gene and SlLOX1, 7, 8 and 14 were the least expressed in the leaf tissue. SILOX13 was not expressed. Among the 13-LOX subfamily members, SILOX3, 4, 11 and 12 were highly expressed whereas SILOX10 was least expressed. 


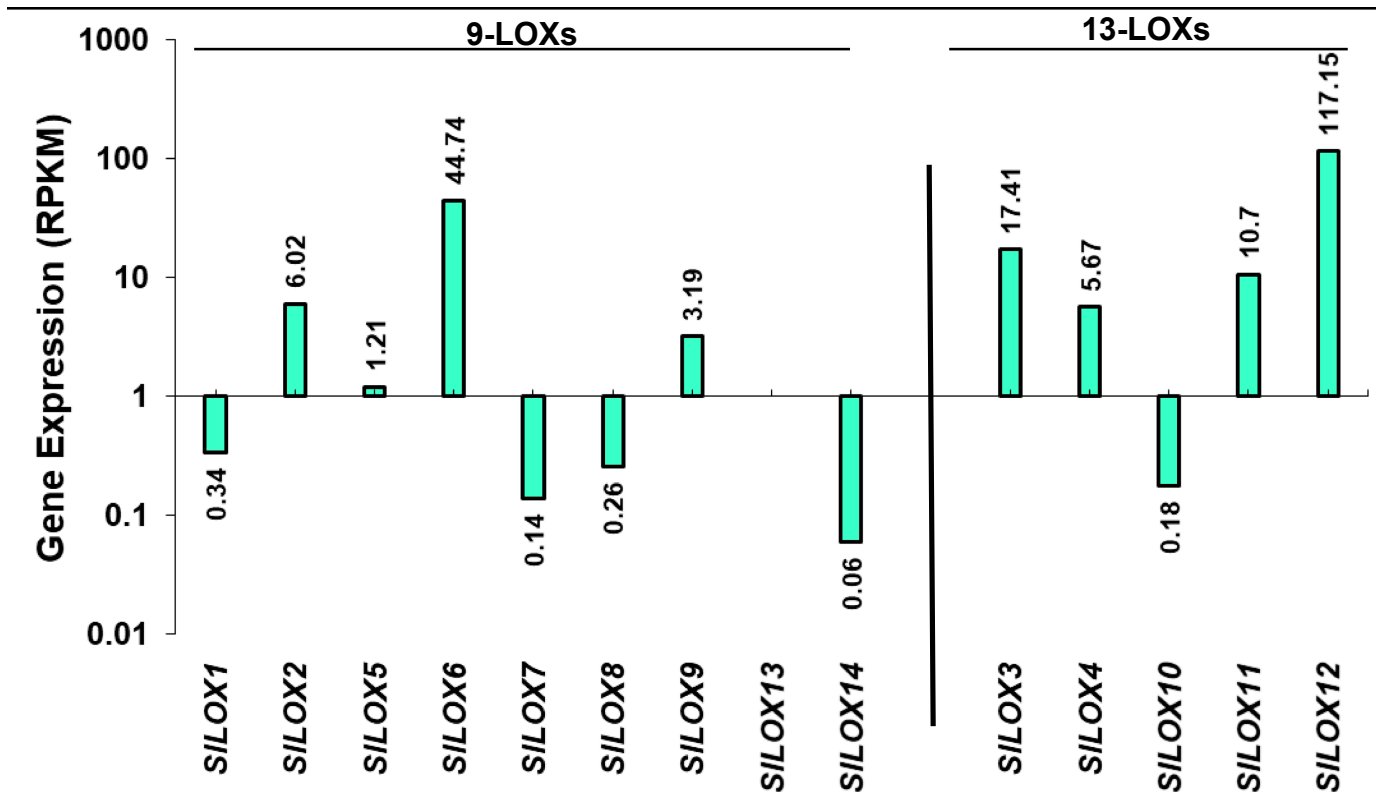

Figure 2. Relative transcript abundance of 9-LOX and 13-LOX gene family members in the leaf tissue of S. lycopersicum cv. Heinz tomato. The bars represent processed reads per kilobase of transcripts per million mapped reads (RPKM) for the tomato leaf LOX genes derived from RNA-seq data (International Tomato Genome Sequencing Consortium [SGN] database) as described in the Materials and Methods section [26]. Y-axis as $\log 2$ scale with inverted axis shows gene members minimally active in the leaf.

3.3. Differential Expression Kinetics of 9- and 13-LOX Genes in S. lycopersicum cv. Ailsa Craig in Response to Different Abiotic Stresses

\subsubsection{Heat Stress}

Time dependent qPCR-based expression patterns of 14 LOX genes in tomato leaves exposed to $42{ }^{\circ} \mathrm{C}$ for up to $24 \mathrm{~h}$ are shown in Figure 3. An immediate downregulation in the expression of five 9-LOX family genes (SILOX1, 2, 7, 8 and 14) and two 13-LOX family members (SILOX3 and 10) within the first $30 \mathrm{~min}$ of heat exposure were apparent (Figure 3; Figure S1). Of these genes, downregulation remained imminent until $6 \mathrm{~h}$ of heat stress for SILOX1, SILOX8 and SILOX14 genes (9-LOX family). It was also noted that the relative expression of SILOX9 (9-LOX family) and SILOX3 and SILOX10 (13-LOX family members) genes remained low during the $24 \mathrm{~h}$ exposure to heat stress (Figure 3 ). In contrast, higher expression of 9-LOX family members, viz., SlLOXs 5, 6, 7 and of 13-LOX family members, namely, SILOX4, SILOX11 and SILOX12, was evident, the expression remaining significantly high throughout the $24 \mathrm{~h}$ exposure except for SILOX11 (Figure 3). Other SILOX gene members that were upregulated at $24 \mathrm{~h}$ stress included 9-LOX members SlLOXs1, 2, 5, 7 and 14 together with that of 13-LOX member SlLOX4. Thus, tomato LOX gene family members selectively and differentially respond to heat stress. 


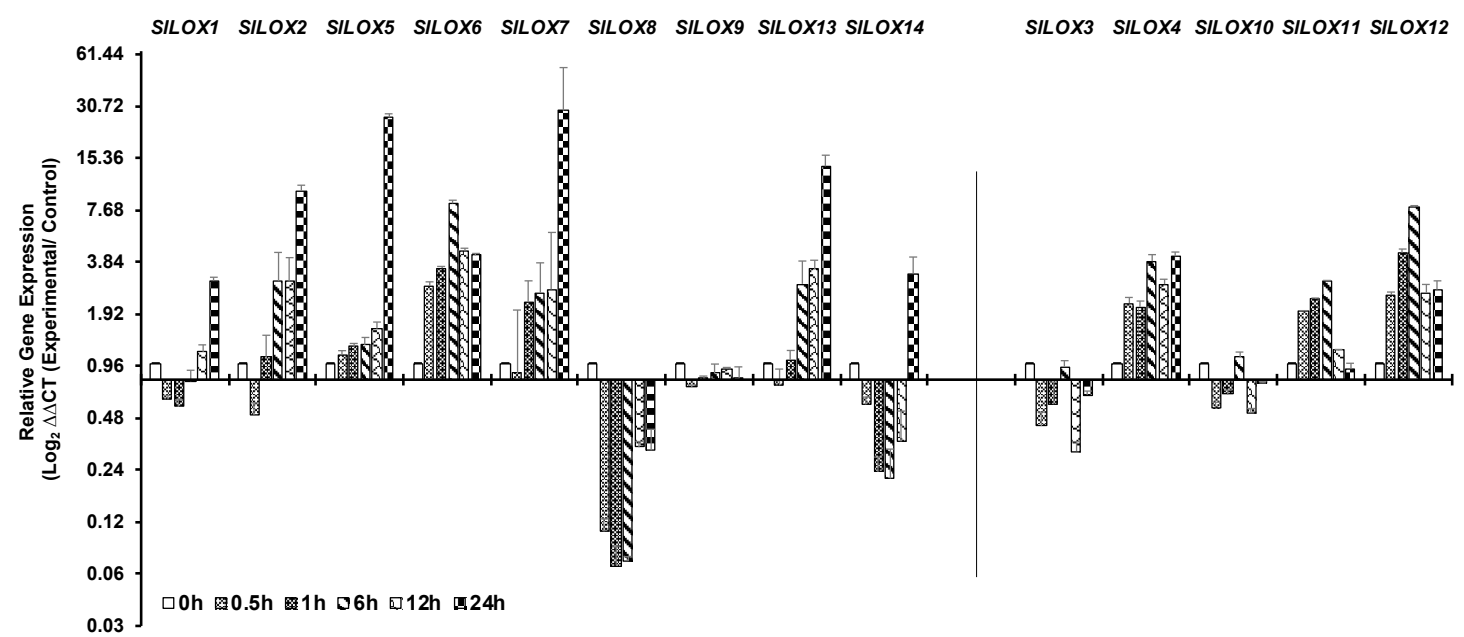

Figure 3. qRT-PCR analysis of tomato (S. lycopersicum cv. Ailsa Craig) LOX gene family members in response to heat stress. Graphical representation qRT-PCR data of tomato 9-LOX genes and 13-LOX genes in response to heat treatment at $42{ }^{\circ} \mathrm{C}$ for up to $24 \mathrm{~h}$. Non-treated control $(0 \mathrm{~h})$ was used as a calibrator in the qRT-PCR data calculation and for defining statistical significance of treatment data points at levels ${ }^{*} p<0.05,{ }^{* *} p<0.01$ and ${ }^{* *} p<0.001$. Details are given in Figure S1. A minimum of three biological replicates, where each biological replicate was comprised of two technical replicates, were used for each time point. Two housekeeping genes, SITIP41 and SIUBI3, were used to normalize the expression of target genes.

\subsubsection{Cold Stress}

Cold stress of tomato leaves was tested at $4{ }^{\circ} \mathrm{C}$ for a duration of $24 \mathrm{~h}$. Time dependent qPCR-based expression patterns of $14 \mathrm{LOX}$ genes in tomato leaves exposed to $4{ }^{\circ} \mathrm{C}$ are shown as bar (Figure 4) and line (Figure S2) graphs. Like the response patterns to heat stress, tomato leaf LOX gene family members differentially responded to cold stress. Expression of 9-LOX SILOX2 and 13-LOX SILOX10 gene members was simultaneously downregulated at $1 \mathrm{~h}$ and remained downregulated throughout the exposure period of $24 \mathrm{~h}$ (Figure 4; Figure S2). The earliest transcript upregulation response, within $1 \mathrm{~h}$ of cold exposure, was apparent for four LOX-9 family gene members (SILOX1, 6, 13 and 14) and three of the LOX-13 family (SlLOX3, 4 and 12) members (Figure 4). A number of the 9-LOX gene family members, viz., SlLOX7, 8, 13 and 14, as well as the 13-LOX member SlLOX12 registered peak activation at $6 \mathrm{~h}$ of cold exposure and were downregulated thereafter; however, their gene expression was still at a higher level compared to that at $1 \mathrm{~h}$ of cold stress. The 9-LOX gene members SILOX5 and SILOX14 as well as 13-LOX SILOX4 maintained a high level of expression at $24 \mathrm{~h}$ of cold exposure. As seen for their response to heat stress above, tomato $L O X$ gene family members also responded differentially to cold stress. 


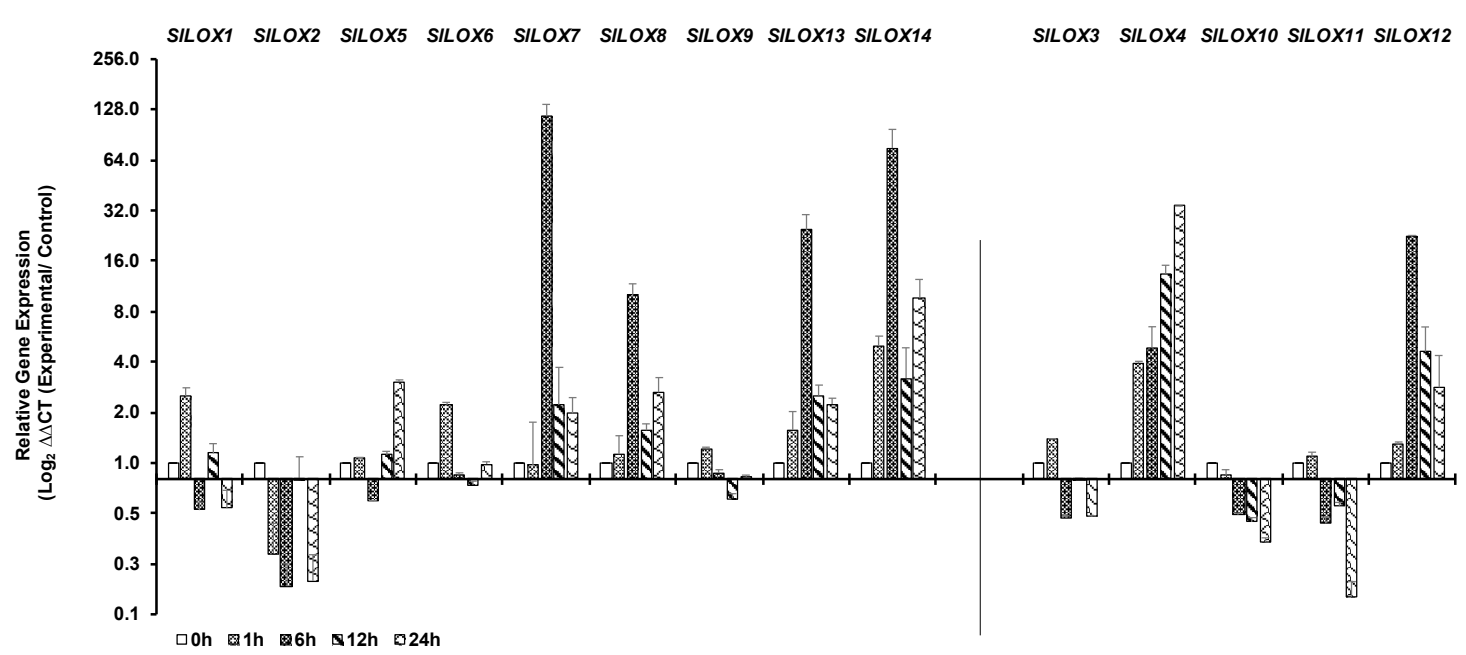

Figure 4. qRT-PCR analysis of tomato (S. lycopersicum cv. Ailsa Craig) LOX gene family members in response to cold stress. Graphical representation of qRT-PCR data of tomato 9-LOX genes and 13-LOX genes in response to cold treatment at $4{ }^{\circ} \mathrm{C}$ for up to $24 \mathrm{~h}$. A non-treated control $(0 \mathrm{~h})$ was used as calibrator in qRT-PCR data calculation and for defining statistical significance of treatment data points at levels ${ }^{*} p<0.05,{ }^{* *} p<0.01$ and ${ }^{* *} p<0.001$. Details are given in Figure S2. A minimum of three biological replicates, where each biological replicate was comprised of two technical replicates, were used for each time point. Housekeeping genes, SITIP41 and SIUBI3, were used to normalize the expression of target genes.

\subsubsection{Drought Stress}

Drought stress led to the downregulation of four 9-LOX family members-SlLOX1, SlLOX5, SILOX7 and SILOX14 as well as of two 13-LOX members SILOX4 and SILOX10 within $24 \mathrm{~h}$ of water retention (bar graph Figure 5; line graph Figure S3). At $48 \mathrm{~h}$ of drought, the expression of seven out of nine 9-LOX family members SILOX1, 2, 6, 7, 8, 9 and 13 and three of the five 13-LOX members SILOX3, SILOX10 and SILOX11 were upregulated. Notably, by $72 \mathrm{~h}$ of drought stress, eight SILOXs 1, 2, 6, 7, 8, 9, 13 and 14 (9-LOX family) were highly upregulated than the $0 \mathrm{~h}$ control and similar trend was observed for the expression of four of the five 13-LOXs SILOX3, 10, 11 and 12 (Figure 5). By $168 \mathrm{~h}$ of drought stress, most of the SILOX members continued to be expressed at a higher level except for SILOX2 and SILOX8 genes. SILOX5 of the 9-LOX family remained suppressed throughout the drought period. 


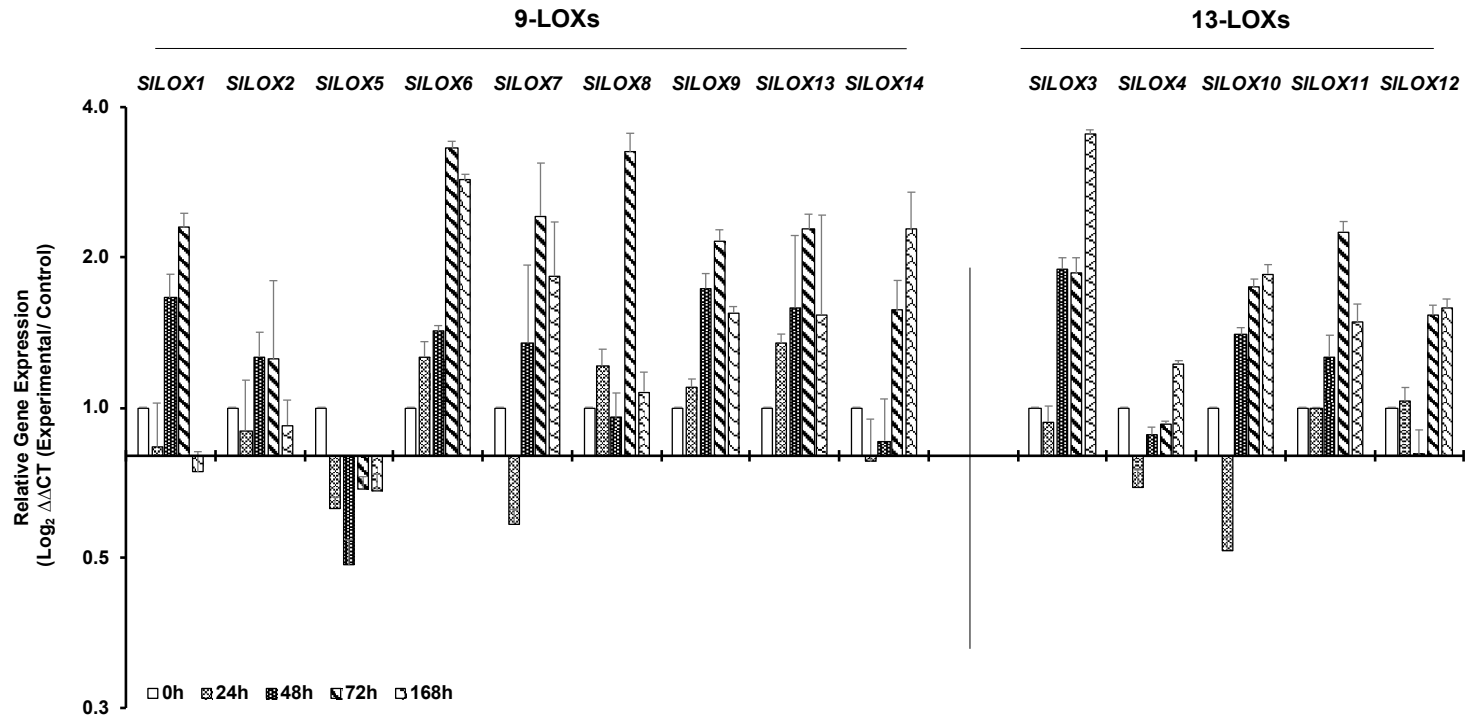

Figure 5. qRT-PCR analysis of tomato (S. lycopersicum cv. Ailsa Craig) LOX gene family members in response to drought stress. Graphical representation of 9-LOX genes and 13-LOX genes in response to drought (water withheld for $168 \mathrm{~h}$ ). A non-treated control $(0 \mathrm{~h})$ was used as a calibrator in qRT-PCR data calculation and for defining statistical significance of treatment data points at levels * $p<0.05$, ${ }^{* *} p<0.01$ and ${ }^{* *} p<0.001$. Details are given in Figure S3. A minimum of three biological replicates, where each biological replicate was comprised of two technical replicates, were used for each time point. SITIP41 and SIUBI3 housekeeping genes were used to normalize the expression of target genes.

\subsubsection{Salt Stress}

Salt stress led to the downregulation of six members of 9-LOX family, viz., SlLOX2, SlLOX5, SILOX7, SILOX8, SILOX13 and SILOX14 and only SILOX12 of the 13-LOX family within $2 \mathrm{~h}$ of treatment (Figure 6). Among these, those members that continued to be further downregulated at 48 or $96 \mathrm{~h}$ of salt treatment include four LOX genes-SILOX5, SILOX8, SILOX14 and SILOX12. The peak upregulation was evident in a number of LOX genes, viz., SlLOX1 (48 h), SlLOX2 (48 h), SlLOX6 (6 h), SlLOX7 (48 h, 96 h), SlLOX9 (48 h), SlLOX3 (48-96 h), SlLOX10 (48-96 h) and SlLOX11 (6 h, 96 h) while SlLOX4 was non-responsive to salt (Figure 6; Figure S4). 


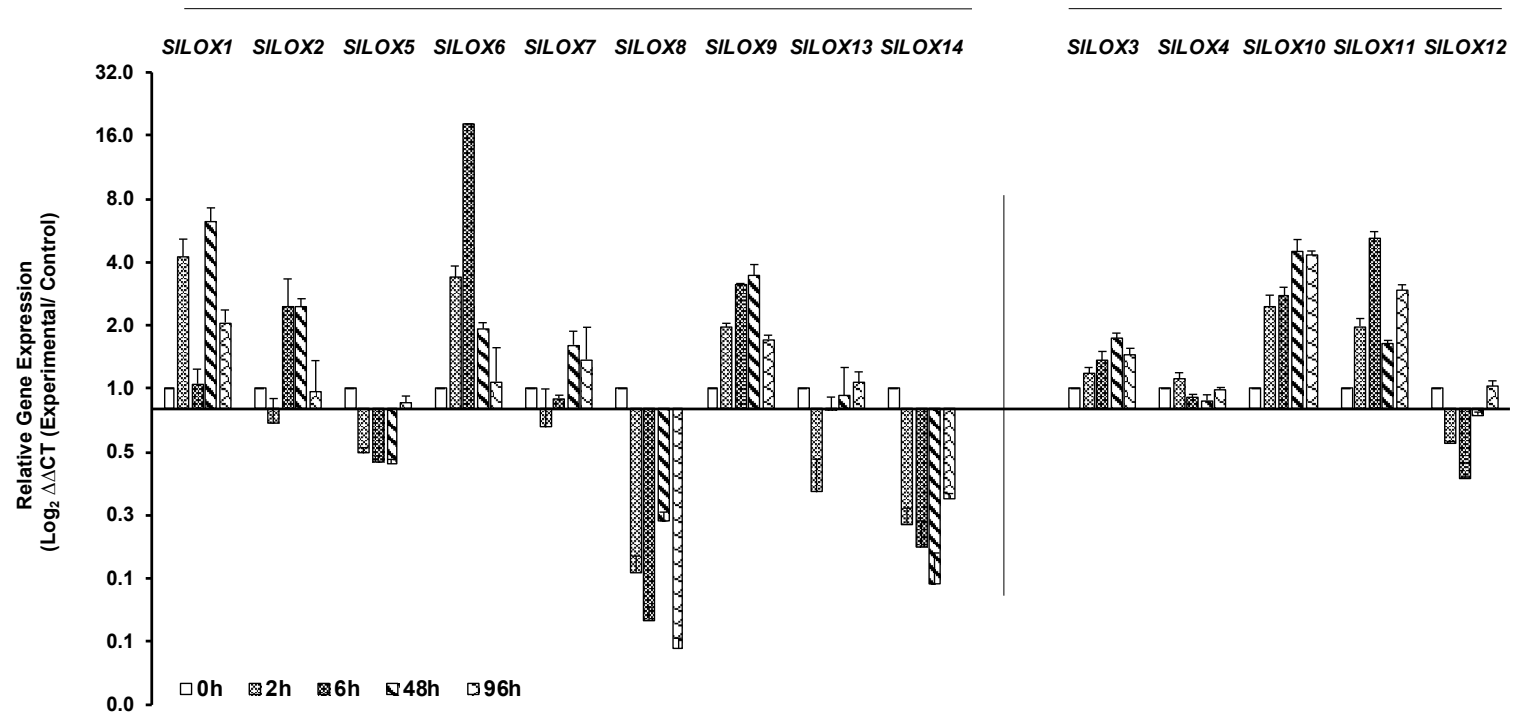

Figure 6. qRT-PCR analysis of tomato (S. lycopersicum cv. Ailsa Craig) LOX gene family members in response to salt stress. Graphical representation of qRT-PCR data of tomato 9-LOX genes and 13-LOX genes in response to salt stress: $200 \mathrm{~mL}$ of $200 \mathrm{mM}$ salt solution was applied daily to plants for $96 \mathrm{~h}$. Non-treated control $(0 \mathrm{~h})$ was used as calibrator in qRT-PCR data calculation and for defining statistical significance of treatment data points at levels ${ }^{*} p<0.05,{ }^{* *} p<0.01$ and ${ }^{* *} p<0.001$. Details are given in Figure S4. A minimum of three biological replicates, where each biological replicate was comprised of two technical replicates, were used for each time point. Housekeeping genes, SITIP41 and SIUBI3, were used to normalize the expression of target genes.

\subsection{Abiotic Stresses-Related Cis-Elements that are Predominant in the SlLOX Promoters}

We next looked for the presence of known stress-specific cis-elements in the LOX family of genes (Table 1). Notably, heat response elements (HSE) were found present in the promoters of both 9-LOX (SlLOX2, 5, 6, 9 and 13) and 13-LOX (SILOX3, 4, 10 and 12) sub-family gene members. Low temperature response elements (LTR) were present in the promoters of three LOX genes, SILOX5 and SILOX7 (9-LOX sub-family) and SILOX10 (13-LOX sub-family). Like the HSE element, drought related-MYB binding site (MBS) was predominant in the promoters of nine LOX genes, SlLOX5, 7, 8, 9, 13 and 14 (9-LOX subfamily) and SlLOX3, 4 and 10 (13-LOX sub-family). MYBHv1-related binding site (CCAAT-box, a stress and defense inducible element) was found on the promoter of SILOX9 (9-LOX sub-family) and SlLOX13 (13-LOX subfamily). 
Table 1. Identification of the abiotic stress response cis-elements in tomato (Solanum lycopersicum L.) 9-LOX and 13 LOX sub-family genes used in this study.

\begin{tabular}{|c|c|c|c|c|c|c|}
\hline Sub-Family & Gene Name & Heat & Cold & Drought & Salt & Others \\
\hline \multirow{9}{*}{ 9-LOX } & SlLOX1 & $?$ & $?$ & $?$ & $?$ & ARE-box \\
\hline & SlLOX2 & HSE & $?$ & $?$ & $?$ & $\begin{array}{c}\text { TC-rich repeats, AT-Rich sequence, } \\
\text { ARE-box }\end{array}$ \\
\hline & SlLOX5 & HSE & LTR & MBS & $?$ & TC-rich repeats \\
\hline & SlLOX6 & HSE, & - & & ? & ARE \\
\hline & SlLOX7 & ? & LTR & MBS & ? & TC-rich repeats, Box-W1, ARE \\
\hline & SlLOX8 & $?$ & $?$ & MBS & $?$ & TC-rich repeats, Box-W1, ARE \\
\hline & SILOX9 & HSE & CСАAT-BOX & MBS, CCAAT-BOX & CCAAT-BOX & ARE \\
\hline & SlLOX13 & HSE & CCAAT-BOX & MBS, CCAAT-BOX & CСАAT-BOX & TC-rich repeats, ARE \\
\hline & SILOX14 & $?$ & ? & MBS & $?$ & TC-rich repeats \\
\hline \multirow{5}{*}{ 13-LOX } & SlLOX3 & HSE & CCAAT-BOX & CCAAT-BOX & CCAAT-BOX & ARE, MBS, TC-rich repeats \\
\hline & SlLOX4 & HSE & $?$ & MBS & $?$ & TC-rich repeats, ARE \\
\hline & SILOX10 & HSE & LTR & MBS & ? & TC-rich repeats, Box-W1, ARE \\
\hline & SlLOX11 & $?$ & ? & $?$ & ? & \\
\hline & SILOX12 & HSE & ? & ? & ? & \\
\hline
\end{tabular}

Question mark (?) indicates that no element associated with a certain response was found in the indicated $L O X$ gene promoter.

\section{Discussion}

Lipoxygenases (LOXs-9-LOX and 13-LOX) catalyze synthesis of important signaling molecules such as jasmonates (jasmonic acid and methyl jasmonate) as well as oxylipins, with significant role(s) in plants during development and in response to abiotic and biotic stresses [8,10,29]. Tomato is susceptible to most abiotic stresses including heat, cold, drought and salinity, each of which can impact tomato yield. Environmental stress-based responses of LOX have been reported previously but they have not been compared under similar isogenic background $[5,9,10]$. We demonstrated here distinct and differential responses of specific gene members of 9-LOX and 13-LOX sub-families in tomato to four separately imposed abiotic stressors and highlight the distinct regulation of LOX gene family members in plant responses to stress. Such information is novel and important for developing molecular markers associated with adverse environmental conditions in order to help breeding for cultivars with higher stress resilience and thereby higher crop productivity.

A collation of the time-dependent responses of single and multiple $L O X$ family of genes specific to each abiotic stress is presented in Figure 7. Three groups emerged distinctly: One included LOX gene members that were downregulated soon after a particular abiotic stress was imposed (immediate downregulation) and included gene members that were unique to each stress; the second group included LOX gene members that immediately upregulated following a particular stress (immediate upregulation) and included gene members that were unique to heat, salt or drought stress and the third group was made of single gene members, which were non-responsive to either heat (LOX9), cold (LOX9) or salt (LOX4) stress (Figure 7). It was also evident that all the LOX genes responded positively or negatively to drought. Thus, these data delineated the positive or negative regulation of each SILOX family member with imposed stress. This novel information on LOX gene family members should be helpful in future studies in developing strategies to combat plant stress, generating stress-resistant transgenic plants and/or searching for unique tomato germplasm rich in a particular LOX gene family member. 


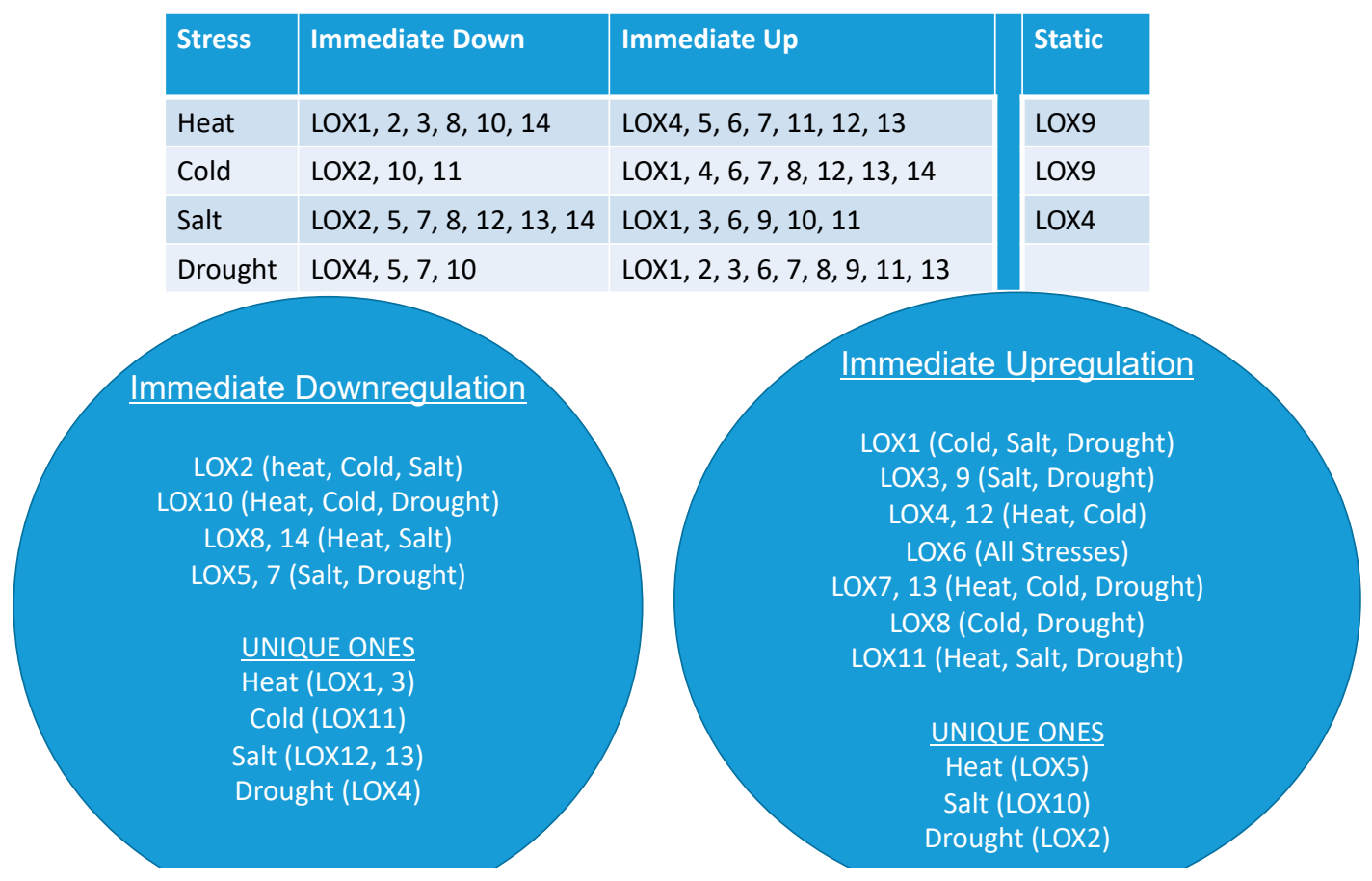

Figure 7. Summary of the immediately downregulated, immediately upregulated and non-responsive (static) tomato 9-LOXs and 13-LOXs genes in response to the four different and independently applied abiotic stresses.

Most of the heat stress-upregulated tomato LOX genes analyzed were found to harbor cis-element HSE in their promoters indicating that related transcription factors might interact and induce their expression. However, other members SILOX1, 7, 8, 12 and 14 did not harbor HSE cis-element in their promoters and yet were induced during heat stress except for the SlLOX8 gene, suggesting that some other unknown factors may facilitate their upregulation during heat stress. Similarly, low temperature responsive motif (LTR, one copy of CCGAAA) was found only in the promoters of two genes SILOX5 and SILOX7, even though many other members were regulated by cold stress. This suggests that a majority of the cold-regulated LOX genes in tomatoes were induced via some other yet unknown transcription factors and/or regulatory genes. Cold exposure is known to increase endogenous JA, for instance, in rice seedlings, which was correlated with the expression of OsLOX2 [49]. Similarly, exogenous MeJA treatment was found to improve freezing tolerance in Arabidopsis seedlings while inhibiting JA biosynthesis and signaling pathway made the seedlings hypersensitive to freezing stress [50].

Any association of previously studied cis-elements in relation to salt stress was not found in our studies. The CCAAT box has been associated with nuclear binding transcription factors that play a role in abiotic stresses, such as drought [51-54], salinity [55,56] and cold [56,57]. Interestingly, some of the LOX gene promoters analyzed in this study were rich in CCAAT box. It is possible that tomato LOX proteins activated in response to salt stress may be a target of these transcription factors and regulatory genes, which utilize CCAAT boxes. In pepper, 9-LOX gene CaLOX1 has been reported to play a role in high salinity and drought tolerance [29] while drought is known to induce PgLOX3 expression in Panax ginseng [9]. Here, a number of SILOX genes were found to differentially respond to drought. Based on the strength of upregulation in response to drought, SLLOXs3, 6 and 8 genes were among the highly expressed LOXs in response to drought. Interestingly, SLOOX3 promoter was found decorated with the MYB binding site (MBS), which may enable its drought inducibility. It is also noted that drought stress activated LOX genes of both 9-LOX and 13-LOX family members.

Salt stress is known to activate tomato LOX genes [5]. Pretreatment of Pisum sativum seedlings with MeJA was also found to counter the salt stress [58] Thus, a role of MeJA/JA as well as related 
metabolites seems to be important for protection against salt stress in plants. The data presented here are in tune with these previous studies and bring to fore differential response of tomato SILOX genes to high salt irrigation.

\section{Conclusions}

This study identified members of the 9-LOX and 13-LOX family of genes in tomato and demonstrated differential and specific expression of each LOX family member in response to four different abiotic stresses. These findings linked and further validated their usefulness as biological markers in stress tolerance/response/mitigation. Three distinct groups emerged: Tomato LOX gene members that were downregulated immediately in response to an abiotic stress and gene members unique to each stress; LOX gene members that were upregulated in response to a particular stress and gene members unique to heat, salt or drought stress and a group of single gene members, which were non-responsive to either heat (SlLOX9), cold (SlLOX9) or salt (SlLOX4) stress. The data presented here are useful and provide a firm background for future investigations in search of robust and novel cis-acting elements differentially present in the promoter regions of the LOX family members in plants. Together, their genetic manipulation should help in devising strategies for improving plant tolerance to different abiotic stresses.

Supplementary Materials: The following are available online at http://www.mdpi.com/2073-4425/10/9/683/s1, Table S1: List of genes and their primer sequences used for quantitative real-time PCR (qRT-PCR) analysis. Figure S1: Line Graphs for qRT-PCR analysis of tomato (S. lycopersicum cv. Ailsa Craig) LOX gene family members in response to heat $\left(42^{\circ} \mathrm{C}\right)$ treatment. Figure S2: Line Graphs for qRT-PCR analysis of tomato (S. lycopersicum cv. Ailsa Craig) LOX gene family members in response to cold $\left(4{ }^{\circ} \mathrm{C}\right)$ treatment. Figure S3: Line Graphs for qRT-PCR analysis of tomato (S. lycopersicum cv. Ailsa Craig) LOX gene family members in response to drought stress. Figure S4: Line Graphs for qRT-PCR analysis of tomato (S. lycopersicum cv. Ailsa Craig) LOX gene family members in response to salt treatment.

Author Contributions: Conceptualization, R.K.U. and A.K.M.; methodology, R.K.U. and A.K.M.; formal analysis, R.K.U. and A.K.M.; investigation, R.K.U.; writing-original draft preparation, R.K.U., A.K.H., and A.K.M.; writing—review and editing, A.K.M.; funding acquisition, A.K.M.

Funding: This research was funded by Agricultural Research Service, United States Department of Agriculture, Project Number 8042-21000-143-00D, P.I. Autar Mattoo.

Acknowledgments: We thank Dan Roberts for his constant support.

Conflicts of Interest: The authors declare no conflict of interest. The funders had no role in the design of the study; in the collection, analyses, or interpretation of data; in the writing of the manuscript, or in the decision to publish the results.

\section{References}

1. Ramakrishna, A.; Ravishankar, G.A. Influence of abiotic stress signals on secondary metabolites in plants. Plant Signal. Behav. 2011, 6, 1720-1731.

2. Mattoo, A.K. Translational research in agricultural biology—Enhancing crop resistivity against environmental stress alongside nutritional quality. Front. Chem. 2014, 2, 30. [CrossRef]

3. Gouinguené, S.P.; Turlings, T.C. The effects of abiotic factors on induced volatile emissions in corn plants. Plant Physiol. 2002, 129, 1296-1307. [CrossRef]

4. Cheong, J.-J.; Choi, Y.D. Methyl jasmonate as a vital substance in plants. Trends Genet. 2003, 19, 409-413. [CrossRef]

5. Dombrowski, J.E. Salt stress activation of wound-related genes in tomato plants. Plant Physiol. 2003, 132, 2098-2107. [CrossRef]

6. Andersson, M.X.; Hamberg, M.; Kourtchenko, O.; Brunnstrom, A.; McPhail, K.L.; Gerwick, W.H.; Feussner, I.; Ellerström, M. Oxylipin profiling of the hypersensitive response in Arabidopsis thaliana: Formation of a novel oxo-phytodienoic acid containing galactolipid, arabidopside E. J. Biol. Chem. 2006, 281, 31528-31537. [CrossRef]

7. Wasternack, C. Jasmonates: An update on biosynthesis, signal transduction and action in plant stress response, growth and development. Ann. Bot. 2007, 100, 681-697. [CrossRef] 
8. Wasternack, C.; Hause, B. Jasmonates: Biosynthesis, perception, signal transduction and action in plant stress response, growth and development. An update to the 2007 review in Annals of Botany. Ann. Bot. 2013, 111, 1021-1058. [CrossRef]

9. Bae, K.-S.; Rahimi, S.; Kim, Y.-J.; Devi, B.S.R.; Khorolragchaa, A.; Sukweenadhi, J.; Silva, J.; Myagmarjav, D.; Yang, D.-C. Molecular characterization of lipoxygenase genes and their expression analysis against biotic and abiotic stresses in Panax ginseng. Eur. J. Plant Pathol. 2016, 145, 331-343. [CrossRef]

10. Sharma, M.; Laxmi, A. Jasmonates: Emerging players in controlling temperature stress tolerance. Front. Plant Sci. 2016, 6, 1859. [CrossRef]

11. Andre, E.; Hou, K. The lipoxydases of seeds of Glycine soja (Sieb) and Phaseolus vulgaris (L.). C. R. Hebd. Seances. Acad. Sci. 1932, 195, 172-174.

12. Porta, H.; Rocha-Sosa, M. Plant lipoxygenases. physiological and molecular features. Plant Physiol. 2002, 130, 15-21. [CrossRef]

13. Ivanov, I.; Heydeck, D.; Hofheinz, K.; Roffeis, J.; O’Donnell, V.B.; Kuhn, H.; Walther, M. Molecular enzymology of lipoxygenases. Arch. Biochem. Biophys. 2010, 503, 161-174. [CrossRef]

14. Schaller, F. Enzymes of the biosynthesis of octadecanoid-derived signalling molecules. J. Exp. Bot. 2001, 52, 11-23. [CrossRef]

15. Schaller, A.; Stintzi, A. Enzymes in jasmonate biosynthesis-structure, function, regulation. Phytochem. 2009, 70, 1532-1538. [CrossRef]

16. Göbel, C.; Feussner, I.; Schmidt, A.; Scheel, D.; Sanchez-Serrano, J.; Hamberg, M.; Rosahl, S. Oxylipin profiling reveals the preferential stimulation of the 9-lipoxygenase pathway in elicitor-treated potato cells. J. Biol. Chem. 2001, 276, 6267-6273. [CrossRef]

17. Andreou, A.; Feussner, I. Lipoxygenases-structure and reaction mechanism. Phytochemistry 2009, 70, 1504-1510. [CrossRef]

18. Howe, G.A.; Jander, G. Plant immunity to insect herbivores. Annu. Rev. Plant Boil. 2008, 59, 41-66. [CrossRef]

19. Liavonchanka, A.; Feussner, I. Lipoxygenases: Occurrence, functions and catalysis. J. Plant Physiol. 2006, 163, 348-357. [CrossRef]

20. Shin, J.H.; Van, K.; Kim, D.H.; Kim, K.D.; Jang, Y.E.; Choi, B.-S.; Kim, M.Y.; Lee, S.-H. The lipoxygenase gene family: A genomic fossil of shared polyploidy between Glycine max and Medicago truncatula. BMC Plant Boil. 2008, 8, 133. [CrossRef]

21. Liu, S.; Liu, X.; Jiang, L. Genome-wide identification, phylogeny and expression analysis of the lipoxygenase gene family in cucumber. Genet. Mol. Res. 2011, 10, 2613-2636. [CrossRef]

22. Umate, P. Genome-wide analysis of lipoxygenase gene family in Arabidopsis and rice. Plant Signal. Behav. 2011, 6, 335-338. [CrossRef]

23. Vogt, J.; Schiller, D.; Ulrich, D.; Schwab, W.; Dunemann, F. Identification of lipoxygenase (LOX) genes putatively involved in fruit flavour formation in apple (Malus $x$ domestica). Tree Genet. Genomes 2013, 9, 1493-1511. [CrossRef]

24. Chen, Z.; Chen, X.; Yan, H.; Li, W.; Li, Y.; Cai, R.; Xiang, Y. the lipoxygenase gene family in poplar: Identification, classification, and expression in response to MeJA treatment. PLoS ONE 2015, 10, e0125526. [CrossRef]

25. Song, H.; Wang, P.; Li, C.; Han, S.; Lopez-Baltazar, J.; Zhang, X.; Wang, X. Identification of lipoxygenase $(L O X)$ genes from legumes and their responses in wild type and cultivated peanut upon Aspergillus flavus infection. Sci. Rep. 2016, 6, 35245. [CrossRef]

26. Upadhyay, R.K.; Mattoo, A.K. Genome-wide identification of tomato (Solanum lycopersicum L.) lipoxygenases coupled with expression profiles during plant development and in response to methyl-jasmonate and wounding. J. Plant Physiol. 2018, 231, 318-328. [CrossRef]

27. Browse, J. Jasmonate passes muster: A receptor and targets for the defense hormone. Annu. Rev. Plant Boil. 2009, 60, 183-205. [CrossRef]

28. Delaplace, P.; Frettinger, P.; Ghanem, M.E.; Blondiaux, A.; Bauwens, J.; Cotton, S.; De Clerck, C.; Dewalque, A.; Guy, J.; Heuze, F. Lipoxygenase pathway and antioxidant system in salt stressed tomato seedlings (Lycopersicon esculentum Mill.). Biotechnol. Agron. Soc. Environ. 2009, 13, 529-536.

29. Lim, C.W.; Han, S.-W.; Hwang, I.S.; Kim, D.S.; Hwang, B.K.; Lee, S.C. The pepper lipoxygenase CaLOX1 plays a role in osmotic, drought and high salinity stress response. Plant Cell Physiol. 2015, 56, 930-942. [CrossRef] 
30. Hou, Y.; Meng, K.; Han, Y.; Ban, Q.; Wang, B.; Suo, J.; Lv, J.; Rao, J. The persimmon 9-lipoxygenase gene DkLOX3 plays positive roles in both promoting senescence and enhancing tolerance to abiotic stress. Front. Plant Sci. 2015, 6, 1073. [CrossRef]

31. Yan, L.; Zhai, Q.; Wei, J.; Li, S.; Wang, B.; Huang, T.; Du, M.; Sun, J.; Kang, L.; Li, C.-B.; et al. Role of tomato lipoxygenase $\mathrm{D}$ in wound-induced jasmonate biosynthesis and plant immunity to insect herbivores. PLoS Genet. 2013, 9, e1003964. [CrossRef]

32. Shen, J.; Tieman, D.; Jones, J.B.; Taylor, M.G.; Schmelz, E.; Huffaker, A.; Bies, D.; Chen, K.; Klee, H.J. A 13-lipoxygenase, TomloxC, is essential for synthesis of C5 flavour volatiles in tomato. J. Exp. Bot. 2014, 65, 419-428. [CrossRef]

33. Clarke, S.M.; Cristescu, S.M.; Miersch, O.; Harren, F.J.M.; Wasternack, C.; Mur, L.A.J. Jasmonates act with salicylic acid to confer basal thermotolerance in Arabidopsis thaliana. New Phytol. 2009, 182, 175-187. [CrossRef]

34. Xu, Y.-H.; Liao, Y.-C.; Zhang, Z.; Liu, J.; Sun, P.-W.; Gao, Z.-H.; Sui, C.; Wei, J.-H. Jasmonic acid is a crucial signal transducer in heat shock induced sesquiterpene formation in Aquilaria sinensis. Sci. Rep. 2016, 6, 21843. [CrossRef]

35. Bell, E.; Mullet, J.E. Characterization of an arabidopsis lipoxygenase gene responsive to methyl jasmonate and wounding. Plant Physiol. 1993, 103, 1133-1137. [CrossRef]

36. Chauvin, A.; Caldelari, D.; Wolfender, J.L.; Farmer, E.E. Four 13-lipoxygenases contribute to rapid jasmonate synthesis in wounded Arabidopsis thaliana leaves: A role for lipoxygenase 6 in responses to long-distance wound signals. New Phytol. 2013, 197, 566-575. [CrossRef]

37. Babenko, L.M.; Shcherbatiuk, M.M.; Skaterna, T.D.; Kosakivska, I.V. Lipoxygenases and their metabolites in formation of plant stress tolerance. Ukr. Biochem. J. 2017, 89, 5-21. [CrossRef]

38. Mehta, R.A.; Cassol, T.; Li, N.; Ali, N.; Handa, A.K.; Mattoo, A.K. Engineered polyamine accumulation in tomato enhances phytonutrient content, juice quality, and vine life. Nat. Biotechnol. 2002, 20, 613-618. [CrossRef]

39. Shukla, V.; Upadhyay, R.K.; Tucker, M.L.; Giovannoni, J.J.; Rudrabhatla, S.V.; Mattoo, A.K. Transient regulation of three clustered tomato class-I small heat-shock chaperone genes by ethylene is mediated by SIMADS-RIN transcription factor. Sci. Rep. 2017, 7, 6474. [CrossRef]

40. Goyal, R.K.; Kumar, V.; Shukla, V.; Mattoo, R.; Liu, Y.; Chung, S.H.; Giovannoni, J.J.; Mattoo, A.K. Features of a unique intronless cluster of class I small heat shock protein genes in tandem with box C/D snoRNA genes on chromosome 6 in tomato (Solanum lycopersicum). Planta 2012, 235, 453-471. [CrossRef]

41. Livak, K.J.; Schmittgen, T.D. Analysis of relative gene expression data using real-time quantitative PCR and the $2^{-\triangle \Delta C T}$ Method. Methods 2001, 25, 402-408. [CrossRef]

42. Expósito-Rodríguez, M.; Borges, A.A.; Borges-Pérez, A.; Pérez, J.A. Selection of internal control genes for quantitative real-time RT-PCR studies during tomato development process. BMC Plant Boil. 2008, 8, 131. [CrossRef]

43. Mascia, T.; Santovito, E.; Gallitelli, D.; Cillo, F. Evaluation of reference genes for quantitative reverse-transcription polymerase chain reaction normalization in infected tomato plants. Mol. Plant Pathol. 2010, 11, 805-816. [CrossRef]

44. Bustin, S.A.; Benes, V.; Garson, J.A.; Huggett, J.; Kubista, M.; Mueller, R.; Nolan, T.; Pfaffl, M.W.; Shipley, G.L.; Vandesompele, J.; et al. The MIQE guidelines: Minimum information for publication of quantitative Real-Time PCR experiments. Clin. Chem. 2009, 55, 611-622. [CrossRef]

45. Lescot, M. PlantCARE, a database of plant cis-acting regulatory elements and a portal to tools for in silico analysis of promoter sequences. Nucleic Acids Res. 2002, 30, 325-327. [CrossRef]

46. Upadhyay, R.K.; Gupta, A.; Soni, D.; Garg, R.; Pathre, U.V.; Nath, P.; Sane, A.P. Ectopic expression of a tomato $D R E B$ gene affects several ABA processes and influences plant growth and root architecture in an age-dependent manner. J. Plant Physiol. 2017, 214, 97-107. [CrossRef]

47. Turner, J.G.; Ellis, C.; Devoto, A. The jasmonate signal pathway. Plant Cell 2011, S153-S164. [CrossRef]

48. León-Morcillo, R.J.; Ángel, J.; Vierheilig, H.; Ocampo, J.A.; García-Garrido, J.M. Late activation of the 9-oxylipin pathway during arbuscular mycorrhiza formation in tomato and its regulation by jasmonate signalling. J. Exp. Bot. 2012, 63, 3545-3558. [CrossRef]

49. Du, H.; Liu, H.; Xiong, L. Endogenous auxin and jasmonic acid levels are differentially modulated by abiotic stresses in rice. Front. Plant Sci. 2013, 4, 397. [CrossRef] 
50. Hu, Y.; Jiang, L.; Wang, F.; Yu, D. Jasmonate regulates the inducer of CBF expression-C-repeat binding factor/DRE binding FACTOR1 cascade and freezing tolerance in Arabidopsis. Plant Cell 2013, 25, 2907-2924. [CrossRef]

51. Nelson, D.E.; Repetti, P.P.; Adams, T.R.; Creelman, R.A.; Wu, J.; Warner, D.C.; Anstrom, D.C.; Bensen, R.J.; Castiglioni, P.P.; Donnarummo, M.G.; et al. Plant nuclear factor Y (NF-Y) B subunits confer drought tolerance and lead to improved corn yields on water-limited acres. Proc. Natl. Acad. Sci. USA 2007, 104, 16450-16455. [CrossRef]

52. Stephenson, T.J.; McIntyre, C.L.; Collet, C.; Xue, G.-P. Genome-wide identification and expression analysis of the NF-Y family of transcription factors in Triticum aestivum. Plant Mol. Boil. 2007, 65, 77-92. [CrossRef]

53. Li, W.-X.; Oono, Y.; Zhu, J.; He, X.-J.; Wu, J.-M.; Iida, K.; Lu, X.-Y.; Cui, X.; Jin, H.; Zhu, J.-K. The Arabidopsis NFYA5 transcription factor is regulated transcriptionally and post transcriptionally to promote drought resistance. Plant Cell 2008, 20, 2238-2251. [CrossRef]

54. Ni, Z.; Hu, Z.; Jiang, Q.; Zhang, H. GmNFYA3, a target gene of miR169, is a positive regulator of plant tolerance to drought stress. Plant Mol. Boil. 2013, 82, 113-129. [CrossRef]

55. Zhao, B.; Ge, L.; Liang, R.; Li, W.; Ruan, K.; Lin, H.; Jin, Y. Members of miR-169 family are induced by high salinity and transiently inhibit the NF-YA transcription factor. BMC Mol. Boil. 2009, 10, 29. [CrossRef]

56. Leyva-González, M.A.; Ibarra-Laclette, E.; Cruz-Ramírez, A.; Herrera-Estrella, L.R. Functional and transcriptome analysis reveals an acclimatization strategy for abiotic stress tolerance mediated by Arabidopsis NF-YA family members. PLoS ONE 2012, 7, e48138. [CrossRef]

57. Shi, H.; Ye, T.; Zhong, B.; Liu, X.; Jin, R.; Chan, Z. AtHAP5A modulates freezing stress resistance in Arabidopsis through binding to CCAAT motif of AtXTH21. New Phytol. 2014, 203, 554-567. [CrossRef]

58. Fedina, I.; Tsonev, T. Effect of pretreatment with methyl jasmonate on the response of Pisum sativum to salt stress. J. Plant Physiol. 1997, 151, 735-740. [CrossRef]

(C) 2019 by the authors. Licensee MDPI, Basel, Switzerland. This article is an open access article distributed under the terms and conditions of the Creative Commons Attribution (CC BY) license (http://creativecommons.org/licenses/by/4.0/). 